\title{
Bilateral Control with Vertical Contracts
}

\author{
Patrick Rey ${ }^{*}$ \\ Thibaud Vergé $* *$
}

July 15, 2003
(*) University of Toulouse (IDEI and GREMAQ), Manufacture des Tabacs, 21 allée de Brienne, 31000 Toulouse, France
Tel: + 33561128640 - e-mail: prey@cict.fr
(**) University of Southampton, Department of Economics, Highfield, Southampton, SO17 1BJ, United Kingdom
Tel: + 442380592530 - e-mail: T.Verge@soton.ac.uk

This paper benefited from helpful discussions with Jean Tirole. We would like to thank Stéphane Caprice and seminar participants at our home institutions and at the University of Essex. Thibaud Vergé would also like to thank the Leverhulme Trust for financial support (CMPO, University of Bristol).

\begin{abstract}
A supplier is known to be subject to opportunism when contracting secretly with downstream competitors, particularly when downstream firms have "passive beliefs." We stress that in many situations, an equilibrium with passive beliefs may not exist and passive beliefs appear less plausible than "wary beliefs," introduced by McAfee and Schwartz. We show that in a broad range of situations, equilibria with wary beliefs exist and reflect opportunism. Last, we confirm the insight, derived by O'Brien and Shaffer using a more ad-hoc equilibrium concept, that RPM eliminates the scope for opportunism.
\end{abstract}




\section{Introduction}

When an upstream firm (a manufacturer, say) supplies several downstream competitors (e.g., retailers), it has an interest to restrict its supply so as to maintain high prices and profits, which it can then share with the downstream firms. However, when dealing with one downstream competitor, the upstream firm has an incentive to "free-ride" on the other competitors. Hart and Tirole (1990) (hereafter HT) have been the first to formally study such opportunism and show that it may prevent the upstream firm from fully exerting its market power. This insight, developed in a context where downstream firms compete à la Cournot, has since been confirmed by O'Brien and Shaffer (1992) (hereafter OS) for the case of Bertrand competition and by McAfee and Schwartz (1994) (hereafter MS) for alternative reactions to contract "renegotiations."

Such opportunistic behavior can arise for several reasons. First, the lack of commitment about future contracts may constitute a key factor. If the manufacturer contracts sequentially with competing retailers, then it has indeed an incentive to free-ride on early signing retailers when negotiating later deals. Second, secret negotiations may also undermine the manufacturer's commitment power. Indeed, even if the manufacturer contracts simultaneously with all its retailers, when deciding whether to pay a franchise fee, say, each retailer may still worry that its competitors receive secret deals (e.g., lower prices per unit). ${ }^{1}$

This opportunism can for example take the form of discounted sales. ${ }^{2}$ It also gives rise to "hold-up" problems that are for example common in the franchise industry: once franchisees have invested in relation-specific assets, launched a new product or more simply paid a high franchise fee, the franchiser might be tempted either to force franchisees out of or to install new outlets in profitable locations. ${ }^{3}$ The risk of opportunism of course reduces franchisees' willingness to join the franchise and prevents the franchisor from fully exerting its market power.

This inability to exert full market power gives in turn the upstream firm an incentive to reduce downstream competition, ${ }^{4}$ e.g., by granting exclusive rights or by integrating one downstream competitor and refusing to deal with its rivals. OS have pointed out that Resale Price Maintenance (RPM), whereby the retail price of a product is set by the manufacturer rather

\footnotetext{
${ }^{1}$ Martin et al. (2001) have experimented alternative contracting situations between an upstream supplier and downstream competitors. They observe that the upstream player was able to maintain output close to the monopoly level significantly less often when making secret offers to the downstream players.

${ }^{2}$ DeGraba (1996, p. 573) mentions for example that "resellers have filed complaints with the FCC that AT\&T will sell time at one rate to them and will then offer a lower rate to a competitor who commits to a larger block of time." OS (p. 306) also discuss some anecdotical evidence.

${ }^{3} \mathrm{MS}$ provide examples of such evidence.

${ }^{4}$ Nondiscrimination rules can as well limit opportunism and thus help the upstream firm exploit its market power. DeGraba and Postlewaite (1992) stress that "most favored customer" clauses may play a similar role, but MS point out that the supplier may still "renegotiate" and offer a lower price / higher fixed fee that will only attract few retailers; such provisions however affect the upstream firm's incentives - see Marx and Shaffer (2002); alternatively, as in the AT\&T example mentioned by DeGraba (1996), resellers can ask for a term-by-term most-favored-customer clause to avoid personalized discounts.
} 
than by the retailer, also allows a manufacturer to eliminate such risk of opportunism; the idea is that, through RPM, a manufacturer can squeeze retail margins (since it then controls both retail and wholesale prices) and become the residual claimant on all retail sales.

We focus here on situations where an upstream supplier secretly contracts with several downstream competitors. A key issue for the analysis of these situations is how downstream firms react to "unexpected" (i.e., out-of-equilibrium) offers. Their willingness to accept such offers depends in turn on their beliefs regarding the offers made to their rivals. Intuitively, there is little scope for opportunism if the competitors are highly "cautious" about unexpected offers. If for example all competitors assume that the supplier is "flooding the market" whenever it proposes to supply below the monopoly price, they would respond negatively to such offers - and the supplier may thus be able to sustain the monopoly price. If instead competitors are more optimistic when receiving unexpected offers, they might be more receptive to "special deals", which in turn may exacerbate the supplier's temptation to flood the market. HT have argued that, in a Cournot-like context where first the upstream firm supplies given quantities at given prices, and then downstream firms compete for consumers, market competition, it is natural to assume that downstream competitors have "passive" or "market-by-market" beliefs, whereby they expect the supplier to stick to the equilibrium contracts with their rivals even if it makes them an out-of-equilibrium offer. The reason is that, in such a Cournot-like context, the quantity actually sold to one downstream firm does not directly affect the profit that the supplier derives from its contracts with the other firms. Therefore, there is arguably no reason to believe that a deviation on one contract would trigger a deviation on other contracts. Passive beliefs are also convenient in that they are usually easy to study, and they have been used as well by OS (in a slightly different way, as we explain below) and by MS. ${ }^{5}$

We stress however below that the strategic "independence" between the contracts signed with the different competitors disappears when downstream competition is more Bertrand-like and/or when downstream firms find out which contracts were signed before actually competing in the final market. In all these cases, the contract signed with one competitor directly affects the profitability of the contracts signed with the other competitors. This has two implications. First, we show that there may not exist any equilibrium with passive beliefs. The reason comes from the fact that, because of contract interdependency, the gain from a multilateral deviation may exceed the total gains of the unilateral deviations. Second, downstream firms should anticipate that, if the supplier deviates with one of them, it has an incentive to change the contracts offered to the others. Passive beliefs thus appear less plausible. We propose to consider instead the notion of wary beliefs introduced by MS: when it receives an unexpected offer, a downstream firm then anticipates that the supplier acts optimally with its rivals, given the offer just received.

We then provide two types of result. First, wary beliefs equilibria still exhibit some degree of opportunism, preventing the upstream firm from fully exploiting its market power. Second,

\footnotetext{
${ }^{5}$ Horn and Wolinsky (1988) use a bilateral Nash-Bargaining approach that also relates somewhat to passive beliefs.
} 
in a linear model wary beliefs equilibria exist even when passive beliefs equilibria fail to exist; in addition, the upstream firm performs better than when downstream firms have passive beliefs, particularly so when retailers compete in prices rather than in quantities. Third, we confirm OS' insight regarding RPM: focusing again on the linear model, when retailers compete in prices there exists a wary beliefs equilibrium where, thanks to RPM, the upstream firm fully exploits its market power.

\section{Framework}

The framework is a simplified version of the model proposed by OS. An upstream manufacturer $M$ sells a product to final consumers through two differentiated retailers $R_{1}$ and $R_{2}$. The manufacturer produces with constant marginal $\operatorname{cost} c$, while each retailer $R_{i}$ operates at zero cost and faces a demand $D_{i}\left(p_{1}, p_{2}\right)$ that is differentiable, downward slopping in $p_{i}$ and decreases when the two prices $p_{1}$ and $p_{2}$ increase uniformly.

To simplify exposition, we will assume that (i) demand is symmetric: ${ }^{6} D_{i}\left(p_{1}, p_{2}\right)=D\left(p_{i}, p_{j}\right)$, with $^{7} \partial_{1} D+\partial_{2} D<0<\partial_{2} D$, and (ii) when the wholesale price is set at marginal cost, price competition leads retailers to charge the same Bertrand price $p^{B}$, characterized by $p^{B}=$ $\arg \max _{p}(p-c) D\left(p, p^{B}\right)$.

These assumptions imply that the inverse demand function is also symmetric: $P_{i}\left(q_{1}, q_{2}\right)=$ $P\left(q_{i}, q_{j}\right)$ and differentiable. We will further assume that $\partial_{1} P<\partial_{2} P<0$ and that, when the wholesale price is set at marginal cost, quantity competition leads the retailers to sell the same Cournot quantity $q^{C}$, characterized by $q^{C}=\arg \max _{q}\left(P\left(q, q^{C}\right)-c\right) q$. Last we suppose that individual revenue functions are concave: for any $q_{i}$ and $q_{j}$ such that $P\left(q_{i}, q_{j}\right)>0$,

$$
\partial_{11}^{2} P\left(q_{i}, q_{j}\right) q_{i}+2 \partial_{1} P\left(q_{i}, q_{j}\right)<0
$$

We model the interactions between the manufacturer and its retailers as a non-cooperative game:

1. $M$ makes retailers take-it-or-leave-it offers; each retailer only observes its own offer and decides whether to accept it or not. For the sake of exposition, we will focus on two-part tariffs, of the form $t_{i}\left(q_{i}\right)=f_{i}+w_{i} q_{i}$, which we will denote by $t_{i}=\left(f_{i}, w_{i}\right) .^{8}$

2. The retailers who have accepted a contract in the first stage compete on the final market.

\footnotetext{
${ }^{6}$ This assumption is made for exposition purposes. The analysis generalizes to asymmetric situations at the cost of significantly heavier notation.

${ }^{7}$ We will denote by $\partial_{i} f$ the partial derivative of $f$ with respect to its $i$ th argument: if $f=f\left(x_{1}, \ldots, x_{n}\right)$, $\partial_{i} f=\partial f / \partial x_{i}$; similarly, $\partial_{i j}^{2} f=\partial^{2} f / \partial x_{i} \partial x_{j}$, and so forth.

${ }^{8}$ In what follows, two-part tariffs are always part of a best response; an equilibrium in two-part tariffs is thus a "true" equilibrium, even considering unrestricted sets of contracts; however, there may exist additional equilibria in which two-part tariffs are not used.
} 
In the following sections, we analyze different situations with respect to the nature of downstream competition and the available information. We will consider both quantity and price competition on the downstream market; in the first case, the retailers set simultaneously the quantity they order and sell on the final market; ${ }^{9}$ in the second case, retailers set retail prices and order quantities so as to satisfy demand. Following MS, we also consider two possible information structures: the accepted contracts can either be observed by both retailers before competing on the downstream market (interim observability game) or not (interim unobservability game).

\section{Passive beliefs}

Analyzing the equilibria of this game requires an assumption on how retailers revise their beliefs about the offers made to rivals, when receiving an "unexpected" (i.e., out-of-equilibrium) offer. We will suppose in this section that retailers do not revise their beliefs: that is, each retailer keeps assuming that the manufacturer offers the equilibrium contract to the rival retailer, even when receiving an out-of-equilibrium offer. This is the so-called "passive beliefs" or "marketby-market conjectures" assumption used both by HT and by MS. ${ }^{10}$

\subsection{Opportunism}

Let us first determine the equilibrium with passive beliefs in a Cournot setting with interim unobservability. With passive beliefs each retailer $R_{i}$ anticipates that its rival receives the equilibrium offer and thus puts the equilibrium quantity $q_{j}^{e}$ on the market. Therefore, in response to a contract $t_{i}, R_{i}$ chooses a quantity

$$
Q_{i}\left(w_{i}\right)=\underset{q_{i}}{\arg \max }\left(P_{i}\left(q_{i}, q_{j}^{e}\right)-w_{i}\right) q_{i}-f_{i},
$$

and accepts the contract as long as the corresponding profit is not negative. The manufacturer uses the franchise fees to extract all retail profits:

$$
f_{i}=\left(P\left(Q_{i}\left(w_{i}\right), q_{j}^{e}\right)-w_{i}\right) Q_{i}\left(w_{i}\right)
$$

and thus sets wholesale prices so as to maximize:

$$
\max _{w_{1}, w_{2}}\left(P\left(Q_{1}\left(w_{1}\right), q_{2}^{e}\right)-c\right) Q_{1}\left(w_{1}\right)+\left(P\left(Q_{2}\left(w_{2}\right), q_{1}^{e}\right)-c\right) Q_{2}\left(w_{2}\right) .
$$

Each wholesale price $w_{i}$ affects this profit only through $\left(P_{i}\left(Q_{i}(),. q_{j}^{e}\right)-c\right) Q_{i}($.$) , which by con-$ struction is maximized for $Q_{i}(c)$. Therefore, in equilibrium, the manufacturer charges wholesale

\footnotetext{
${ }^{9}$ In order to simplify the analysis, we assume that the retailers directly set quantities. As in HT, we could have assumed that the retailers order quantities first and then compete in prices.

${ }^{10}$ Here beliefs are conjectures on the part of the firm, following the receipt of an out-of-equilibrium offer, about the offer being made to the rival. Although the term "conjectures" might seem more appropriate than beliefs (which might seem to refer to the "type" of the rival firm), we use the terminology established by MS throughout this paper.
} 
prices equal to the marginal cost; there thus exists a unique equilibrium, which coincides with the standard Cournot equilibrium:

Proposition 1 In a quantity competition setting with interim unobservability, there exists a unique equilibrium with passive beliefs. The manufacturer sets marginal transfer prices equal to marginal cost $\left(w_{i}^{e}=w_{j}^{e}=c\right)$, which leads to Cournot quantities and profit.

This result, originally due to HT, is very intuitive. With passive beliefs each retailer $R_{i}$ anticipates that its rival will stick to the equilibrium quantity $q_{j}^{e}$ and is thus willing to pay up to $P\left(q_{i}+q_{j}^{e}\right)$ for any given quantity $q_{i}$. Since $M$ can monitor the retail choice of $q_{i}$ through the wholesale price $w_{i}$ and recover any expected profit through the franchise fee $f_{i}$, it will "choose" $q_{i}$ so as to maximize $\left(P\left(q_{i}+q_{j}^{e}\right)-c\right) q_{i}$, which is achieved for the Cournot best response to $q_{j}^{e}$. As in HT, the manufacturer is thus subject to opportunism and even non linear wholesale contracts do not allow it to fully exploit its monopoly power.

\subsection{Nonexistence problems}

Passive beliefs are convenient and usually lead to tractable results. They are also close in spirit to the "contract equilibria" introduced by Crémer and Riordan (1987) and used in a Bertrand setting by OS. This concept focuses on pairwise deviations: $M$ and $R_{i}$ sign the best contract, given the contract signed with $R_{j}$; in contrast, a perfect equilibrium with passive beliefs must also resist multilateral deviations, where the manufacturer simultaneously deviates with both retailers. Hence, any passive beliefs equilibrium is a contract equilibrium, but a contract equilibrium is not a passive beliefs equilibrium if it does not survive to multilateral deviations.

It is easy to check that multilateral deviations are not more relevant than unilateral deviations in the above Cournot setting where retailers never observe each other's contracts. The producer's profit is of the form:

$$
\left(w_{1}-c\right) q_{1}+f_{1}+\left(w_{2}-c\right) q_{2}+f_{2},
$$

where $f_{i}$ and $q_{i}$ denote respectively the fee paid and the quantity actually sold by $R_{i}$. Since $R_{i}$ does not observe the offer $t_{j}$ made to its rival before accepting or rejecting its own offer, $f_{i}$ cannot depend on $t_{j}$. In addition, when retailers compete in a Cournot fashion and never observe each other's contracts, the actual quantity $q_{i}$ also depends only on the offer $t_{i}$ made to $R_{i}$, and not on $t_{j}$ (it depends of course on $R_{i}$ 's belief about $t_{j}$, but not on the actual $t_{j}$ ). Therefore, the two contracts affect the profit expression (3) in a separable way: the first two terms of the profit expression depend on $t_{1}$ only, while the other two terms depend on $t_{2}$ only. The impact of a multilateral deviation is thus simply the sum of the impacts of each unilateral deviation, implying that any contract equilibrium is also a perfect equilibrium with passive beliefs (that is, the two concepts coincide here).

We stress below that multilateral deviations may matter and prevent the existence of an equilibrium when retailers observe each other's contracts before choosing their quantities (interim 
observability) and/or when retailers compete in prices à la Bertrand. The quantity eventually sold by one retailer then depends on the offer actually made to the other retailer, thereby destroying the above-mentioned separability. ${ }^{11}$

Consider for example the case where retailers compete à la Bertrand and never observe each other's contracts. Then, the price charged by $R_{i}$ still depends only on the offer made to that retailer:

$$
p_{i}=P\left(w_{i}\right) \equiv \underset{p}{\arg \max }\left(p-w_{i}\right) D\left(p, p_{j}^{e}\right),
$$

but the quantity $q_{i}$ eventually sold by $R_{i}$ depends on both wholesale prices:

$$
q_{i}=Q_{i}\left(w_{1}, w_{2}\right) \equiv D_{i}\left(P\left(w_{1}\right), P\left(w_{2}\right)\right)
$$

Therefore, the profit expression (3) is no longer separable in $w_{1}$ and $w_{2}$ : each wholesale price $w_{i}$ has an effect on the wholesale revenue $\left(w_{j}-c\right) Q_{j}\left(w_{1}, w_{2}\right)$ generated by the other retailer and the impact of a multilateral deviation thus no longer adds-up those of unilateral deviations. Whenever this cross effect is sufficiently important, the manufacturer's objective is not concave and a multilateral deviation can be attractive even when unilateral deviations are not. The following proposition shows that indeed, multilateral deviations destroy the unique candidate equilibrium identified by OS when the two retailers are sufficiently good substitutes. Let

$$
\varepsilon \equiv-\frac{p^{B} \partial_{1} D\left(p^{B}, p^{B}\right)}{D\left(p^{B}, p^{B}\right)} \text { and } \varepsilon_{S} \equiv \frac{p^{B} \partial_{2} D\left(p^{B}, p^{B}\right)}{D\left(p^{B}, p^{B}\right)}
$$

denote the direct and cross elasticities of the demand, evaluated at the Bertrand equilibrium. We have:

Proposition 2 In a price competition setting with interim unobservability:

(i) if the cross elasticity of substitution is small, namely, if $\varepsilon_{S}<\varepsilon / 2$, there exists a unique equilibrium with passive beliefs; the manufacturer sets marginal transfer prices equal to marginal $\operatorname{cost}\left(w_{i}^{e}=w_{j}^{e}=c\right)$, which leads to Bertrand prices and profit;

(ii) if the cross elasticity of substitution is large $\left(\varepsilon_{S}>\varepsilon / 2\right)$, there exists no perfect Bayesian equilibrium with passive beliefs.

Proof. In the price competition setting, if there exists an equilibrium of the interim unobservability game with passive beliefs, this equilibrium is identical to the contract equilibrium characterized by OS. Hence the unique equilibrium involves differentiable wholesale tariffs, with

\footnotetext{
${ }^{11} \mathrm{MS}$ already mentions that existence can be an issue in the interim observability case. McAfee and Schwartz (1995) explore this issue in more detail - they also emphasize that even a pairwise-proof equilibrium may fail to exist when the number of competitors increases, since the candidate equilibrium would generate losses.

Segal and Whinston (2003) note a similar existence problem when the manufacturer faces non-constant returns to scale. There again, the quantity sold to one retailer affects the profit achieved with the other retailer and multilateral deviations become an issue.
} 
marginal wholesale prices equal to the manufacturer's marginal cost, $c$ and retail prices equal to $p^{B} .12$

Consider now a "double-sided deviation" based on wholesale prices $\left(w_{1}, w_{2}\right)$; under passive beliefs, $R_{i}$ is willing to pay up to

$$
f_{i}=\left(P\left(w_{i}\right)-w_{i}\right) D\left(P\left(w_{i}\right), p^{B}\right),
$$

where $P(w)=\underset{p}{\arg \max } \pi_{R}(p, w) \equiv(p-w) D\left(p, p^{B}\right)$. The manufacturer's profit is:

$$
\begin{aligned}
\pi_{P}\left(w_{1}, w_{2}\right) \equiv & \left\{\left(w_{1}-c\right) D\left(P\left(w_{1}\right), P\left(w_{2}\right)\right)+\left(P\left(w_{1}\right)-w_{1}\right) D\left(P\left(w_{1}\right), p^{B}\right)\right. \\
& \left.+\left(w_{2}-c\right) D\left(P\left(w_{2}\right), P\left(w_{1}\right)\right)+\left(P\left(w_{2}\right)-w_{2}\right) D\left(P\left(w_{2}\right), p^{B}\right)\right\}
\end{aligned}
$$

A bilateral deviation of the form $w_{1}=w_{2}=c+\varepsilon$ is profitable whenever $\partial_{11}^{2} \pi_{P}(c, c)+$ $\partial_{12}^{2} \pi_{P}(c, c)>0$. From the above expression,

$$
\partial_{12}^{2} \pi_{P}(c, c)=2 \partial_{2} D\left(p^{B}, p^{B}\right) P^{\prime}(c) .
$$

To compute $\partial_{11}^{2} \pi_{P}(c, c)$, note that

$$
\pi_{P}(w, c)=\pi_{R}(P(w), c)+\text { constant. }
$$

Therefore,

$$
\partial_{1} \pi_{P}(w, c)=\partial_{1} \pi_{R}(P(w), c) P^{\prime}(w),
$$

and thus (using $P(c)=p^{B}, \partial_{1} \pi_{R}(P(c), c)=0$ and $P^{\prime}(c)=-\frac{\partial_{12}^{2} \pi_{R}\left(p^{B}, c\right)}{\partial_{11}^{2} \pi_{R}\left(p^{B}, c\right)}$ )

$$
\partial_{11}^{2} \pi_{P}(c, c)=\partial_{11}^{2} \pi_{R}\left(p^{B}, c\right)\left[P^{\prime}(c)\right]^{2}=-\partial_{12}^{2} \pi_{R}\left(p^{B}, c\right) P^{\prime}(c)=\partial_{1} D\left(p^{B}, p^{B}\right) P^{\prime}(c) .
$$

A bilateral deviation of the form $w_{1}=w_{2}=c+\varepsilon$ is thus profitable when

$$
\partial_{11}^{2} \pi_{P}(c, c)+\partial_{12}^{2} \pi_{P}(c, c)=\left[\partial_{1} D\left(p^{B}, p^{B}\right)+2 \partial_{2} D\left(p^{B}, p^{B}\right)\right] P^{\prime}(c)>0,
$$

that is (since $P^{\prime}(c)>0$ ), when

$$
\frac{\varepsilon_{S}}{\varepsilon}=\frac{\partial_{2} D\left(p^{B}, p^{B}\right)}{-\partial_{1} D\left(p^{B}, p^{B}\right)}>\frac{1}{2} .
$$

When instead this condition is not satisfied, it is easy to check that the profit function $\pi_{P}\left(w_{1}, w_{2}\right)$ is concave and that OS' contract equilibrium thus constitutes a true perfect Bayesian equilibrium.

Thus, no equilibrium exists in the Bertrand-like framework with interim unobservability when the elasticity of substitution is higher than half of the direct elasticity at the Bertrand

\footnotetext{
${ }^{12}$ OS show that these are the only contract equilibria, without any prior restriction on the contracts. All equilibria lead to the same retail prices and quantities, and one of them involves two-part tariffs of the form $T_{i}\left(q_{i}\right)=\pi_{i}^{B}+c q_{i}$.
} 
equilibrium prices. ${ }^{13}$ A similar observation applies when retailers observe each other's contracts before choosing their prices or quantities. The quantity $q_{i}$ sold by $R_{i}$ then depends again on the actual offers made to the two retailers, and multilateral deviations may be profitable even when unilateral deviations are not. Suppose for example that demand is linear and given by:

$$
P\left(q_{1}, q_{2}\right)=1-q_{1}-\beta q_{2}
$$

The parameter $\beta$ reflects the degree of substitution between the two retailers: $\beta=0$ corresponds to local monopolies, and $\beta=1$ to perfect substitution. When retailers compete à la Bertrand and never observe each other's contracts, from the above proposition there is no equilibrium when $\beta>\frac{1}{2}$; when retailers observe each other's contracts (whether they compete in a Bertrand or Cournot fashion), there is similarly no equilibrium when $\beta>\widehat{\beta} \approx 0.806 .{ }^{14,15}$

\section{Wary beliefs}

Passive or "market-by-market" beliefs are plausible in the above Cournot context since, from the point of view of the upstream monopolist, the two retailers then form two separate markets (even though retailers themselves perceive a strong interdependency). The producer has no incentive to change the offer to one retailer when altering the contract signed with the rival retailer: what matters is the retailer's anticipation about the quantity bought by its rival, not the quantity actually bought.

As already noted, this independence disappears when retailers either compete in a Bertrand fashion or observe rivals' contracts before ordering their own quantities. In these situations, the contract signed with one retailer affects the supplier's sales to the other retailers. Recognizing this point, MS suggested that retailers' beliefs should be consistent with the producer's incentives. We will show that, when demand is linear, opting for consistent beliefs also helps restoring the existence of an equilibrium. ${ }^{16}$

\footnotetext{
${ }^{13}$ With $n$ downstream competitors, the nonexistence condition becomes $\left(\varepsilon_{S} / \varepsilon>1 / 2(n-1)\right)$; it thus becomes more likely to be satisfied as the number of competitors increases. For example, in the linear demand highlighted below, if the inverse demand function is given by $P_{i}(q)=1-q_{i}-\beta \Sigma_{j \neq i} q_{j}$, the equilibrium fails to exist when $\beta>1 / n$.

${ }^{14} \mathrm{~A}$ proof this statement is presented in the Web appendix to this paper, available at http://www.idei.asso.fr/English/ECv/CvChercheurs/EcvRey.html.

${ }^{15}$ Caprice (2002) considers the case where contracts remain unobserved but retailers observe each other's acceptance decisions. This observability of acceptance decisions does not raise existence problems, but alters the equilibrium contracts when retailers have access to an alternative source of supply (a competitive but less efficient fringe, say); the manufacturer has then an incentive to lower the marginal wholesale price when acceptance decisions are observed: this makes one retailer "more aggressive" when the other refuses the contract, and thus reduces retailers' rents.

${ }^{16}$ There may also exist equilibria with other types of beliefs. For example, "symmetric conjectures", in which each retailer believes that the producer always treat both retailers in the same way (even out of the equilibrium), generates an equilibrium with monopoly prices (hence the producer can fully exploits its monopoly power under this particular type of belief). We show in this paper that monopoly prices cannot be sustained with wary beliefs.
} 
Note that retailers must form beliefs not only about the contract offered to their rivals, but also about the quantities or prices charged by their rivals (which in turn depend on rivals's beliefs). With passive beliefs, this issue is moot: since $R_{i}$ believes that $R_{j}$ received the equilibrium contract, it must believe that $R_{j}$ anticipates that its rival also received the equilibrium contract and will thus sell the equilibrium quantity (in the Cournot-like setting) or charge the equilibrium price (in the Bertrand-like framework). $R_{i}$ thus chooses the best response to the equilibrium quantity $q_{j}^{e}$ or price $p_{j}^{e}$, given the contract offered to itself. However, if $R_{i}$ believes that the producer also offered an unexpected offer to $R_{j}, R_{i}$ is likely to anticipate a change in $R_{j}$ 's behavior. It is natural to assume that $R_{i}$ will then expect $R_{j}$ to optimally react to the producer's unexpected offer. MS thus proposed the following notion of wary beliefs:

\section{Definition 1 Wary beliefs}

When $R_{i}$ receives a contract $t_{i}$, it believes that:

1. the manufacturer expects it to accept this contract,

2. the manufacturer offers $R_{j}(j \neq i)$ the contract $T_{j}\left(t_{i}\right)$ that is the best for the monopolist, among all contracts acceptable to $R_{j}$,

3. $R_{j}$ reasons the same way.

\subsection{Quantity competition with interim unobservability}

We first note that wary beliefs coincide with passive beliefs when retailers compete in quantities and contracts are never observable. When being offered a contract $t_{i}=\left(f_{i}, w_{i}\right), R_{i}$ expects $M$ to offer $R_{j}$ a contract $T_{j}\left(t_{i}\right)=\left(F_{j}\left(t_{i}\right), W_{j}\left(t_{i}\right)\right)$ and $R_{j}$ to accept it. $R_{i}$ then chooses a quantity, $Q_{i}\left(t_{i}\right)$, that constitutes the best reply to $R_{j}$ 's anticipated quantity; $Q_{1}\left(t_{1}\right)$ and $Q_{2}\left(t_{2}\right)$ therefore satisfy the recursive condition:

$$
Q_{i}\left(t_{i}\right)=\underset{q_{i}}{\arg \max }\left(P\left(q_{i}, Q_{j}\left(T_{j}\left(t_{i}\right)\right)\right)-w_{i}\right) q_{i} .
$$

In addition, $R_{i}$ will accept a contract $\left(w_{i}, f_{i}\right)$ if and only if the franchise fee $f_{i}$ is lower than the retail expected profit, that is

$$
f_{i} \leq\left(P\left(Q_{i}\left(t_{i}\right), Q_{j}\left(T_{j}\left(t_{i}\right)\right)\right)-w_{i}\right) Q_{i}\left(t_{i}\right) .
$$

It remains to determine the retailers' beliefs $T_{j}\left(t_{i}\right)$. With wary beliefs, when $R_{i}$ is offered a tariff $t_{i}$ it anticipates that $M$ offers and $R_{j}$ accepts a tariff $T_{j}\left(t_{i}\right)$ given by:

$$
\begin{aligned}
T_{j}\left(t_{i}\right) & =\underset{\left(w_{j}, f_{j}\right)}{\arg \max }\left(w_{i}-c\right) Q_{i}\left(t_{i}\right)+f_{i}+\left(w_{j}-c\right) Q_{j}\left(t_{j}\right)+f_{j} \\
\text { s.t. } & : \quad f_{j} \leq\left(P\left(Q_{j}\left(t_{j}\right), Q_{i}\left(T_{i}\left(t_{j}\right)\right)\right)-w_{j}\right) Q_{j}\left(t_{j}\right)
\end{aligned}
$$

Segal and Whinston (2003) point out that allowing the producer to offer menus of contracts and choose quantities once retailers have accepted or rejected the offer reduces somewhat the set of possible equilibria for any belief, and that all equilibrium outcomes must converge towards the competitive one when a strict competitive equilibrium exists (that is, when the marginal cost of production is strictly increasing). 
The solution to this program does not depend on $t_{i}$. Therefore, $R_{i}$ 's conjectures are independent of the contract it received and thus $T_{j}\left(t_{i}\right)=t_{j}^{*}$, the equilibrium offer. In this Cournot framework with interim unobservability, wary beliefs are thus equivalent to passive beliefs: ${ }^{17}$

Proposition 3 In the quantity competition setting with interim unobservability, wary beliefs are equivalent to passive beliefs; there thus exists a unique equilibrium with wary beliefs characterized by

$$
w_{i}^{C, U}=w_{j}^{C, U}=c \text { and } q_{i}^{C, U}=q_{j}^{C, U}=q^{C} .
$$

This equivalence is the underlying reason behind the plausibility of passive beliefs already noted by HT for the Cournot setting with interim unobservability. We now show that this equivalence breaks down when contracts are interim observable or when firms compete in a Bertrand setting.

Remark. Although we use MS definition of wary beliefs, our transposition differs from theirs, which relies on the retail equilibrium that would be generated by wholesale prices $\left(w_{1}, w_{2}\right)$ if these prices were common knowledge. More precisely, letting $\pi\left(w_{i}, w_{j}\right)$ and $q\left(w_{i}, w_{j}\right)$ denote firm $i$ 's profit and input demand when both firms know that the wholesale prices are $w_{i}$ and $w_{j}$, MS characterize wary beliefs as follows:

$$
\begin{aligned}
W_{j}\left(w_{i}\right) & =\underset{w_{j}}{\arg \max }\left[\left(w_{i}-c\right) q\left(w_{i}, W_{j}\left(w_{i}\right)\right)+\left(w_{j}-c\right) q\left(w_{j}, W_{i}\left(w_{j}\right)\right)+\pi\left(w_{j}, W_{i}\left(w_{j}\right)\right)\right], \\
F_{j}\left(w_{i}\right) & =\pi\left(W_{j}\left(w_{i}\right), W_{i}\left(W_{j}\left(w_{i}\right)\right)\right) .
\end{aligned}
$$

However, $q\left(w_{i}, W_{j}\left(w_{i}\right)\right)$ is the quantity that $R_{i}$ would sell if it was common knowledge that $R_{i}$ faces $w_{i}$ and $R_{j}$ faces $W_{j}\left(w_{i}\right)$, which is incompatible with $R_{j}$ selling $q\left(w_{j}, W_{i}\left(w_{j}\right)\right)$. Using instead the behavioral functions $Q_{i}\left(t_{i}\right)$ allows us to avoid this inconsistency. ${ }^{18}$

\subsection{Price competition with interim unobservability}

Let us now consider the case where retailers compete in prices and never observe each other's contracts. When being offered a contract $t_{i}=\left(f_{i}, w_{i}\right), R_{i}$ expects $M$ to offer $R_{j}$ a contract $T_{j}\left(t_{i}\right)=\left(W_{j}\left(t_{i}\right), F_{j}\left(t_{i}\right)\right)$ and $R_{j}$ to accept it. Then, $R_{i}$ 's price must constitute its best reply to its rival's anticipated price:

$$
P_{i}\left(t_{i}\right)=\underset{p_{i}}{\arg \max }\left(p_{i}-w_{i}\right) D\left(p_{i}, P_{j}\left(T_{j}\left(t_{i}\right)\right)\right)
$$

\footnotetext{
${ }^{17}$ Throughout the paper, superscripts $C$ and $B$ will respectively refer to Cournot and Bertrand downstream competition, while $M$ refers to the monopoly outcome. Superscipts $U$ and $O$ refer respectively to the cases of interim unobservabilty and interim observability.

${ }^{18}$ With MS formulation, in the case of interim unobservability the manufacturer's profit is separable in $w_{i}$ and $w_{j}$, whatever the type of retail competition. With our formulation, in the case of Bertrand competition the producer's profit is no longer separable even with interim unobservability and wary beliefs thus differ from passive beliefs.
} 
In addition, $R_{i}$ accepts a contract $\left(f_{i}, w_{i}\right)$ if and only if the franchise fee $f_{i}$ is lower than the retail expected profit, that is

$$
f_{i} \leq\left(P_{i}\left(t_{i}\right)-w_{i}\right) D\left(P_{i}\left(t_{i}\right), P_{j}\left(T_{j}\left(t_{i}\right)\right)\right) .
$$

Conversely, when $R_{i}$ is offered $t_{i}$, with wary beliefs it anticipates that $M$ offers and $R_{j}$ accepts the wholesale contract $T_{j}\left(t_{i}\right)$ given by:

$$
\begin{aligned}
T_{j}\left(t_{i}\right) & =\underset{\left(w_{j}, f_{j}\right)}{\arg \max }\left(w_{i}-c\right) D\left(P_{i}\left(t_{i}\right), P_{j}\left(t_{j}\right)\right)+f_{i}+\left(w_{j}-c\right) D\left(P_{j}\left(t_{j}\right), P_{i}\left(t_{i}\right)\right)+f_{j} . \\
\text { s.t. } & : \quad f_{j} \leq\left(P_{j}\left(t_{j}\right)-w_{j}\right) D\left(P_{j}\left(t_{j}\right), P_{i}\left(T_{i}\left(t_{j}\right)\right)\right)
\end{aligned}
$$

In contrast with the case of Cournot competition, we cannot directly rule out anymore that beliefs depend also on franchise fees - in which case the participation constraint is not guaranteed to be binding. This potential dependence is however rather artificial, since it comes from the fact that $R_{i}$ 's beliefs $T_{j}\left(t_{i}\right)$ affect its price response $P_{i}\left(t_{i}\right)$, which in turn affects the determination of $T_{j}($.$) ; thus, while franchise-dependent beliefs could self-sustain themselves, such dependence$ is not triggered by fundamental variables. We therefore restrict our attention on beliefs that do not depend on franchise fees, for which (5) boils down to:

$$
\begin{gathered}
W_{j}\left(w_{i}\right)=\underset{w_{j}}{\arg \max }\left[\left(w_{i}-c\right) D\left(P_{i}\left(w_{i}\right), P_{j}\left(w_{j}\right)\right)+\left(w_{j}-c\right) D\left(P_{j}\left(w_{j}\right), P_{i}\left(w_{i}\right)\right)\right. \\
\left.\quad+\left(P_{j}\left(w_{j}\right)-w_{j}\right) D\left(P_{j}\left(w_{j}\right), P_{i}\left(W_{i}\left(w_{j}\right)\right)\right)\right] \\
\text { and } F_{j}\left(w_{i}\right)=\left.\quad\left(P_{j}\left(w_{j}\right)-w_{j}\right) D\left(P_{j}\left(w_{j}\right), P_{i}\left(W_{i}\left(w_{j}\right)\right)\right)\right|_{w_{j}=W_{j}\left(w_{i}\right)}
\end{gathered}
$$

A more important difference with the case of Cournot competition is that the objective function in (6) is no longer separable in $w_{i}$ and $w_{j}$. This implies that wary beliefs now depend on $w_{i}$ and thus differ from passive beliefs.

The following proposition provides some characterization of wary beliefs equilibria. We first consider symmetric equilibria and show that the monopoly outcome cannot be sustained. We then show that, when demand is linear, there exists indeed a (symmetric) wary equilibrium, where each belief $W_{i}$ is a polynomial function of $w_{j}$.

Proposition 4 When contracts are interim unobservable and retailers compete à la Bertrand, wary beliefs do not coincide with passive beliefs. If retailers have wary beliefs that only depend on wholesale prices, then:

(i) In any symmetric equilibrium, the equilibrium retail price is lower than the monopoly price;

(ii) if demand is linear, there exists a unique equilibrium with polynomial beliefs, and this equilibrium is symmetric.

Proof. See Appendix A. 
Therefore, in contrast to the case of passive beliefs, there exists an equilibrium with wary beliefs when demand is linear. Retailers being now more "suspicious" about the manufacturer's behavior, out-of-equilibrium offers are more likely to be rejected, which ensures the existence of an equilibrium. In the set of polynomial beliefs, this equilibrium is unique (beliefs are then affine functions of wholesale prices) and symmetric. However, if wary beliefs reduce the scope for opportunism, they do not completely eliminate this problem and the manufacturer cannot maintain monopoly prices. The opportunism problem is thus "robust", in the sense that it does not critically depend on a particular choice of equilibrium concept (contract equilibrium, passive or wary beliefs equilibria, and Cournot or Bertrand retail competition).

\subsection{Interim observability}

Finally, we assume in this section that contracts are interim observable: contract offers are initially secret (acceptance decisions are therefore based on beliefs) but retailers observe the accepted contracts before competing (in prices or in quantities) on the final market. The equilibrium of the retail competition subgame is therefore the solution of a standard Cournot or Bertrand-fashion competition game for which the firms face costs equal to $w_{i}$ and $w_{j}$. In what follows, we denote by $q^{R}\left(w_{i}, w_{j}\right)$ and $\pi^{R}\left(w_{i}, w_{j}\right)$, the retail quantity and profit emerging from the retail competition subgame. ${ }^{19}$

When being offered a contract $t_{i}=\left(f_{i}, w_{i}\right), R_{i}$ again expects $M$ to offer and $R_{j}$ to accept a tariff $T_{j}\left(t_{i}\right)$ given by:

$$
\begin{aligned}
T_{j}\left(t_{i}\right) & =\underset{\left(w_{j}, f_{j}\right)}{\arg \max }\left(w_{i}-c\right) q^{R}\left(w_{i}, w_{j}\right)+f_{i}+\left(w_{j}-c\right) q^{R}\left(w_{j}, w_{i}\right)+f_{j} \\
\text { s.t. } & : \quad f_{j} \leq \pi^{R}\left(w_{j}, W_{i}\left(t_{j}\right)\right)
\end{aligned}
$$

Clearly, the solution of this program does not depend on $f_{i}$ and, since the objective function is strictly increasing in $f_{j}$, the constraint must be binding. The rival's anticipated contract is thus given by:

$$
W_{j}\left(w_{i}\right)=\underset{w_{j}}{\arg \max }\left(w_{i}-c\right) q^{R}\left(w_{i}, w_{j}\right)+\left(w_{j}-c\right) q^{R}\left(w_{j}, w_{i}\right)+\pi^{R}\left(w_{j}, W_{i}\left(w_{j}\right)\right)
$$

and

$$
F_{j}\left(w_{i}\right)=\pi^{R}\left(W_{j}\left(w_{i}\right), W_{i}\left(W_{j}\left(w_{i}\right)\right)\right) .
$$

The following proposition provides some characterization of wary beliefs equilibria under interim observability: ${ }^{20}$

\footnotetext{
${ }^{19}$ Denoting by $q^{C}\left(w_{i}, w_{j}\right)$ and $p^{B}\left(w_{i}, w_{j}\right)$ the standard Cournot quantities and Bertrand prices for wholesale prices $w_{i}$ and $w_{j}$, the quantity sold by $R_{i}$ is $q_{i}=q^{R}\left(w_{i}, w_{j}\right)=q^{C}\left(w_{i}, w_{j}\right)$ when retailers compete in a Cournot fashion and $q_{i}=q^{R}\left(w_{i}, w_{j}\right)=D\left(p^{B}\left(w_{i}, w_{j}\right), p^{B}\left(w_{j}, w_{i}\right)\right)$ when they compete in a Bertrand fashion.

${ }^{20}$ For a complete analysis of the interim unobservability case, see the Web appendix to this paper, available at http://www.idei.asso.fr/English/ECv/CvChercheurs/EcvRey.html.
} 
Proposition 5 When contracts are interim observable, wary beliefs no longer coincide with passive beliefs. If retailers have wary beliefs, then:

(i) In any symmetric equilibrium, the equilibrium retail price is lower than the monopoly price;

(ii) if demand is linear, there exists a unique equilibrium with polynomial beliefs, and this equilibrium is symmetric.

\subsection{Price comparisons}

Wary beliefs mitigate somewhat the scope for opportunism. In particular, they eliminate the equilibrium nonexistence problem when demand is linear. We also checked that, while wary beliefs coincide with passive beliefs in the case of Cournot competition and interim unobservability, in all other cases wary beliefs (symmetric) equilibrium prices are below the monopoly level but above the level achieved in passive beliefs equilibria (when they exist). The intuition is that when a retailer is offered a higher wholesale price than expected, with wary beliefs he anticipates that the other retailer also receives a higher wholesale price, ${ }^{21}$ and is thus willing to pay a higher franchise fee than with passive beliefs; this, in turn, encourages the manufactuer to offer higher wholesale prices, leading to higher retail prices as well.

More precisely, for the unique equilibrium with polynomial beliefs, and for any $0<\beta<1$ and $0 \leq c<1$ (with $p_{P}^{i, j}$ denoting the candidate equilibrium retail price with passive beliefs):

$$
p_{P}^{C, O}<p^{B}=p_{P}^{B, U}<p_{P}^{B, O}<p_{P}^{C, U}=p^{C}=p^{C, U}<p^{C, O}<p^{B, O}<p^{B, U}<p^{M} .
$$

Thus, with wary beliefs prices are lower with retail Cournot competition than with retail Bertrand competition. This comes from the fact that, while price competition is more intense than quantity competition for given wholesale prices, the manufacturer's opportunism is moderated in the Bertrand setting, leading to higher wholesale prices - and sufficiently higher to offset the lower retail margin. Consider for example the interim unobservability case. When retailers compete in quantities, wary beliefs then coincide with passive beliefs and lead to the standard Cournot outcome. In the Bertrand setting, the actual quantities sold by the two retailers are interdependent: retailers anticipate that their rival will be charged a higher price when they are themselves charged a higher price, which in turn encourages the manufacturer to maintain relatively higher prices. A similar argument applies when the contracts are interim observable, although actual quantities are now interdependent in both settings. The gap between the equilibrium prices under Cournot and Bertrand is reduced, since contract interim observability makes the outcome more competitive in Bertrand but less competitive in Cournot.

\footnotetext{
${ }^{21}$ That is, $W_{i}^{\prime}>0$ (given the linearity of demand and of retail responses, $\partial_{12}^{2} \pi_{P}=\partial_{1} q_{2}^{R}+\partial_{2} q_{1}^{R}>0$ ).
} 


\section{Application: the anticompetitive impact of Resale Price Main- tenance}

\subsection{Contract equilibrium}

OS have shown that, when retailers compete in prices and never observe rivals' contracts, in all "contract equilibria" the manufacturer's opportunism leads retailers to charge the standard Bertrand price $\left(p^{B}\right)$; OS have also shown that RPM, in the form of a price ceiling, solves the opportunism problem:

Proposition 6 (O'Brien and Shaffer, RJE 1992) In all contract equilibria, the manufacturer charges a marginal price equal to its marginal cost and retailers charge the Bertrand price $\left(p_{i}^{*}=p^{B}\right)$. When Resale Price Maintenance (or a price ceiling) is allowed, there exists a contract equilibrium where the manufacturer maintains monopoly prices $\left(p_{i}=p^{M}\right)$ and achieves the monopoly profit.

As in HT for Cournot downstream competition, the scope for opportunism comes from the fact that, when negotiating with $R_{i}, M$ has an incentive to free-ride on $R_{j}$ 's margin. A solution to this free-riding problem is to squeeze $R_{j}$ 's margin, which can be achieved by imposing a price ceiling equal to the (marginal) wholesale price: this removes the manufacturer's incentives to engage in opportunism and restores the credibility of monopoly prices.

\subsection{Wary beliefs}

As already discussed, the concept of "contract equilibrium" is intuitive but does not coincide with the equilibrium of a well-defined game. In addition, the related notion of passive beliefs equilibrium is subject to nonexistence problems, which potentially limits the relevance of the analysis. However, using wary beliefs in the above linear model, we can check that the insight of OS is robust.

We introduce $R P M$ as follows:

1. $M$ makes a take-it-or-leave offer to each retailer; each retailer only observes its own offer and decides whether to accept it. Each contract now consists of a two-part tariff, together with an imposed retail price.

2. The retailers who have accepted a contract in the first stage set the retail price imposed by the manufacturer and sell so as to satisfy demand.

There is thus no actual retail competition; and when receiving an offer $\left(f_{i}, w_{i} ; p_{i}\right), R_{i}$ must anticipate not only the two-part tariff $t_{j}$ offered to its competitor, but also the imposed retail price $p_{j}$. We have: 
Proposition 7 In the price competition setting with RPM contracts, when demand is linear there exists an equilibrium with wary beliefs where prices and the producer's profit are at the monopoly level.

Proof. See Appendix B.

The intuition is the same as in OS's analysis of contract equilibria. The manufacturer's opportunism problem arises when retail margins are strictly positive. Then, when $M$ signs a contract with $R_{1}, M$ is interested by the quantity sold through $R_{2}$ because of its margin $w_{2}-c$ but does not take into account $R_{2}$ ' margin $p_{2}-w_{2}$. Whenever this retail margin is positive, $M$ does not entirely internalize the effect of a cut in price $p_{1}$, which leads to prices lower than the monopoly level. With $R P M, M$ can however set both the wholesale prices and the retail prices at the monopoly level, thereby eliminating retailers' margins and the source of its opportunistic behavior.

Remark: Cournot competition. RPM may not solve the opportunism problem in a Cournotlike setting. Consider for example a framework à la Kreps and Scheinkman (1983) in which retailers first-order quantities and then compete in prices:

1. $M$ makes a take-it-or-leave offer to each retailer; each retailer only observes its own offer and decides whether to accept it. Each contract now consists of a two-part tariff, together with an imposed retail price.

2. The retailers who have accepted a contract in the first stage order quantities and resell them on the retail market at the price imposed by the manufacturer.

It is easy to check that in this framework RPM does not have any effect and thus cannot eliminate opportunism. Once $M$ has convinced $R_{i}$ to accept a contract $t_{i}$, the profit it will make with that retailer is not affected by the contract $t_{j}$ negotiated with $R_{j}$, since $M$ does not care about the quantity eventually sold by $R_{i}$, but only about the quantity ordered by $R_{i}$, which itself only depends only on $t_{i}$. In order to eliminate any scope for opportunism, the profit achieved with one retailer would need to depend on the contract offered to the rival retailer e.g., through buy-back or returns policies.

\section{Concluding remarks}

The above analysis shows that wary beliefs provide a reasonable alternative to passive or marketby-market beliefs whenever the contract actually offered to one downstream firm affects the upstream monopolist's incentives when dealing with the other downstream firm. Whenever such interdependence arises: (i) an equilibrium with passive beliefs may not exist, due to the fact that multilateral deviations may become attractive; and (ii) passive beliefs differ from and are arguably less plausible than wary beliefs. We also show that an equilibrium with wary beliefs 
exists in the linear model and that this equilibrium still reflects the "opportunism" problem generated by contract secrecy.

O'Brien and Shaffer discuss several cases in which $R P M$ has been adopted by an upstream supplier in order to exert its market power. ${ }^{22}$ Our analysis shows that, while the contract equilibrium concept adopted by O'Brien and Shaffer is debatable, their insight is indeed robust: when considering equilibria with wary beliefs, RPM allows the manufacturer to solve its commitment problem and maintain monopoly prices.

Another way to test the robustness of this insight consists in reverting to public contracts, but assuming that the manufacturer deals with the retailers in sequence, as in the following three-stage game:

1. $M$ publicly offers $R_{1}$ a wholesale two-part tariff $t_{1}(q)=f_{1}+w_{1} q$, which $R_{1}$ publicly accepts or refuses.

2. $M$ publicly offers $R_{2}$ a wholesale two-part tariff $t_{2}(q)=f_{2}+w_{2} q$, which $R_{2}$ publicly accepts or refuses.

3. Retailers who have accepted a contract set their prices and order quantities so as to satisfy demand.

It can then be checked that the vertically integrated outcome cannot be supported in equilibrium, for the same reason as before: when negotiating $R_{2}$ 's contract, $M$ has an inventive to free-ride on $R_{1}$ 's retail margin and generate a lower price $p_{2}<p_{2}^{m}$. RPM again restores monopoly profits: if contracts include an imposed retail price, the equilibrium involves $w_{1}=p_{1}=p_{1}^{m}$, which induces $p_{2}=p_{2}^{m}$ and thus allows the manufacturer to generate and recover the monopoly profit. Hence RPM restores the vertically integrated outcome that would otherwise be eroded by competition. As in OS, a price ceiling suffices to obtain this result, by removing the manufacturer's incentives for opportunism. ${ }^{23}$

\footnotetext{
${ }^{22}$ OS provides two statements along these lines, one by a grocery store owner and one by the president of the US leading supplier of golf equipment.

${ }^{23}$ An industry-wide retail price floor (applying to both retailers) would also solve the manufacturer's commitment problem (see Rey and Tirole (1997)).
} 


\section{A Price competition and interim unobservability}

We study here price competition with interim unobservability, and focus on beliefs $W_{j}\left(w_{i}\right)$ that depend only on the wholesale price (not on the franchise fee). $R_{i}$ 's best reply to the $R_{j}$ 's anticipated retail price $P_{j}\left(W_{j}\left(w_{i}\right)\right)$, for $i \neq j=1,2$, is then given by:

$$
P_{i}\left(w_{i}\right)=\underset{p_{i}}{\arg \max }\left(p_{i}-w_{i}\right) D\left(p_{i}, P_{j}\left(W_{j}\left(w_{i}\right)\right)\right) .
$$

The manufacturer chooses the equilibrium wholesale prices, $w_{1}^{*}$ and $w_{2}^{*}$, so as to maximise its profit

$$
\begin{aligned}
\pi_{P}\left(w_{1}, w_{2}\right)= & \left(w_{1}-c\right) D\left(P_{1}\left(w_{1}\right), P_{2}\left(w_{2}\right)\right)+\left(P_{1}\left(w_{1}\right)-w_{1}\right) D\left(P_{1}\left(w_{1}\right), P_{1}\left(W_{1}\left(w_{1}\right)\right)\right) \\
+ & \left(w_{2}-c\right) D\left(P_{2}\left(w_{2}\right), P_{1}\left(w_{1}\right)\right)+\left(P_{2}\left(w_{2}\right)-w_{2}\right) D\left(P_{2}\left(w_{2}\right), P_{2}\left(W_{2}\left(w_{2}\right)\right)\right) ;
\end{aligned}
$$

where the wary beliefs satisfy $\partial_{1} \pi_{P}\left(W_{1}(w), w\right)=0$ and $\partial_{2} \pi_{P}\left(w, W_{2}(w)\right)=0$.

\section{A.1 Any symmetric equilibrium retail price is strictly lower than the monopoly price}

Focusing on symmetric equilibria, the manufacturer's program can be rewritten as follows:

$$
\left(w^{*}, w^{*}\right)=\underset{\left(w_{1}, w_{2}\right)}{\arg \max } \pi_{P}\left(w_{1}, w_{2}\right)
$$

where

$$
\begin{aligned}
\pi_{P}\left(w_{1}, w_{2}\right)= & \pi^{M}\left(P\left(w_{1}\right), P\left(w_{2}\right)\right)+\left(P\left(w_{1}\right)-w_{1}\right)\left(D\left(P\left(w_{1}\right), P\left(W\left(w_{1}\right)\right)\right)-D\left(P\left(w_{1}\right), P\left(w_{2}\right)\right)^{\prime}\right. \\
& +\left(P\left(w_{2}\right)-w_{2}\right)\left(D\left(P\left(w_{2}\right), P\left(W\left(w_{2}\right)\right)\right)-D\left(P\left(w_{2}\right), P\left(w_{1}\right)\right)\right)
\end{aligned}
$$

and

- $\pi^{M}\left(p_{1}, p_{2}\right)=\left(p_{1}-c\right) D\left(p_{1}, p_{2}\right)+\left(p_{2}-c\right) D\left(p_{1}, p_{2}\right)$;

- the retailers' pricing strategy is

$$
P(w)=\underset{p}{\arg \max }(p-w) D(p, P(W(w))) ;
$$

- and the wary beliefs $W(w)$ are such that

$$
\partial_{1} \pi_{P}(W(w), w)=0
$$

A.1.1 The equilibrium retail price is lower than the monopoly price $\left(p^{*} \leq p^{M}\right)$

Let us first show that any symmetric equilibrium retail price must be lower than the monopoly price, characterized by $\partial_{1} \pi^{M}\left(p^{M}, p^{M}\right)=0$.

- First-order condition of the manufacturer's maximization program: 
The first-order condition of the manufacturer's program is $\partial_{1} \pi_{P}\left(w^{*}, w^{*}\right)=0$, that is, with $p^{*}=P\left(w^{*}\right)$,

$$
\left[\partial_{1} \pi^{M}\left(p^{*}, p^{*}\right)+\left(p^{*}-w^{*}\right) \partial_{2} D\left(p^{*}, p^{*}\right)\left(W^{\prime}\left(w^{*}\right)-1\right)\right] P^{\prime}\left(w^{*}\right)=0 .
$$

- Step 1: $P^{\prime}\left(w^{*}\right) \neq 0$

The first-order condition of the retailers' program writes as:

$$
(P(w)-w) \partial_{1} D(P(w), P(W(w)))+D(P(w), P(W(w)))=0 .
$$

Differentiating $(A 1)$ at $w=w^{*}$ yields: ${ }^{24}$

$$
\begin{aligned}
\left(P^{\prime}\left(w^{*}\right)-1\right) \partial_{1} D+\left(p^{*}-w^{*}\right)( & \left.\partial_{11}^{2} D+\partial_{12}^{2} D \cdot W^{\prime}\left(w^{*}\right)\right) P^{\prime}\left(w^{*}\right) \\
& \left(\partial_{1} D+\partial_{2} D \cdot W^{\prime}\left(w^{*}\right)\right) P^{\prime}\left(w^{*}\right)=0,
\end{aligned}
$$

or

$$
\left[2 \partial_{1} D+\partial_{2} D \cdot W^{\prime}\left(w^{*}\right)+\left(p^{*}-w^{*}\right)\left(\partial_{11}^{2} D+\partial_{12}^{2} D \cdot W^{\prime}\left(w^{*}\right)\right)\right] P^{\prime}\left(w^{*}\right)=\partial_{1} D .
$$

$\partial_{1} D<0$ then implies $P^{\prime}\left(w^{*}\right) \neq 0$.

- Step 2: $p^{*} \leq p^{M}$

Since $P^{\prime}\left(w^{*}\right) \neq 0$, the first-order condition of the manufacturer's program simplifies to

$$
\partial_{1} \pi^{M}\left(p^{*}, p^{*}\right)=-\left(p^{*}-w^{*}\right) \partial_{2} D\left(p^{*}, p^{*}\right)\left(W^{\prime}\left(w^{*}\right)-1\right) .
$$

Differentiating $(W)$ with respect to $w$ yields:

$$
\partial_{11}^{2} \pi_{P}(W(w), w) W^{\prime}(w)+\partial_{12}^{2} \pi_{P}(W(w), w)=0
$$

which, evaluated at $w=w^{*}$, leads to:

$$
\partial_{11}^{2} \pi_{P}\left(w^{*}, w^{*}\right) \cdot W^{\prime}\left(w^{*}\right)+\partial_{12}^{2} \pi_{P}\left(w^{*}, w^{*}\right)=0 \Leftrightarrow W^{\prime}\left(w^{*}\right)=-\frac{\partial_{12}^{2} \pi_{P}\left(w^{*}, w^{*}\right)}{\partial_{11}^{2} \pi_{P}\left(w^{*}, w^{*}\right)} .
$$

The second-order conditions of the manufacturer's program thus requires $\left|W^{\prime}\left(w^{*}\right) \leq 1\right|$.

Evaluating $(A 1)$ at $w=w^{*}$ yields

$$
-\left(p^{*}-w^{*}\right) \partial_{1} D\left(p^{*}, p^{*}\right)=D\left(p^{*}, p^{*}\right),
$$

and thus $p^{*}>w^{*}$. Finally, since $\partial_{2} D\left(p^{*}, p^{*}\right)>0$ :

- either $W^{\prime}\left(w^{*}\right)<1$, in which case $(A 3)$ implies $\partial_{1} \pi^{M}\left(p^{*}, p^{*}\right)<0$; the concavity of the function $\pi^{M}$ then ensures that $p^{*}<p^{M}$;

- or $W^{\prime}\left(w^{*}\right)=1$, in which case $p^{*}=p^{M}$.

\footnotetext{
${ }^{24}$ The derivatives of the demand function $D$ are all evaluated at $\left(p^{*}, p^{*}\right)$.
} 


\section{A.1.2 The monopoly price is not an equilibrium price $\left(\Leftrightarrow W^{\prime}\left(w^{*}\right) \neq 1\right)$.}

In order to sustain the monopoly price as an equilibrium price, the equilibrium wholesale price $\left(w^{*}=w^{M}\right)$ must satisfy:

$$
D\left(p^{M}, p^{M}\right)+\left(p^{M}-w^{M}\right) \partial_{1} D\left(p^{M}, p^{M}\right)=0 \text { and } W^{\prime}\left(w^{M}\right)=1 .
$$

The second condition implies that $\partial_{11}^{2} \pi_{P}\left(w^{M}, w^{M}\right)+\partial_{12}^{2} \pi_{P}\left(w^{*}, w^{*}\right)=0$, and we thus need to look at third-order effects. We now show that the gain from a symmetric deviation $\left(w^{M}+\varepsilon, w^{M}+\varepsilon\right)$ is strictly positive for $\varepsilon>0$ (small enough), thereby ruling out $w^{M}$ as a possible equilibrium wholesale price. The gain from such a deviation is:

$$
\delta(\varepsilon)=\pi_{P}\left(w^{M}+\varepsilon, w^{M}+\varepsilon\right)-\pi_{P}\left(w^{M}, w^{M}\right) .
$$

If $w^{M}$ is a symmetric equilibrium wholesale price, since $\partial_{11}^{2} \pi_{P}\left(w^{M}, w^{M}\right)+\partial_{12}^{2} \pi_{P}\left(w^{M}, w^{M}\right)=0$ and $\delta^{\prime}(0)=0$, we also have $\delta^{\prime \prime}(0)=0$. Using the symmetry of the profit function $\pi_{P}$, the thirdorder derivative is given by:

$$
\delta^{\prime \prime \prime}(0)=2 \partial_{111}^{3} \pi_{P}\left(w^{M}, w^{M}\right)+6 \partial_{112}^{3} \pi_{P}\left(w^{M}, w^{M}\right) .
$$

Differentiating (A4) with respect to $w$ at $w=w^{M}$ yields, using $W^{\prime}\left(w^{M}\right)=1$ and the symmetry of the profit function $\pi_{P}$ :

$$
\partial_{111}^{3} \pi_{P}\left(w^{M}, w^{M}\right)+3 \partial_{112}^{3} \pi_{P}\left(w^{M}, w^{M}\right)+\partial_{11}^{2} \pi_{P}\left(w^{M}, w^{M}\right) W^{\prime \prime}\left(w^{M}\right)=0 .
$$

Using $(A 6)$, we can rewrite $(A 5)$ as:

$$
\delta^{\prime \prime \prime}(0)=-2 \partial_{11}^{2} \pi_{P}\left(w^{M}, w^{M}\right) W^{\prime \prime}\left(w^{M}\right) .
$$

We thus need to show that $W^{\prime \prime}\left(w^{M}\right)>0$.

The beliefs $W(w)$ are such that $\partial_{1} \pi_{P}\left(W_{1}(w), w\right)=0$, that is:

$$
\begin{gathered}
P^{\prime}(W(w))\left[\partial_{1} \pi^{M}(P(W(w)), P(w))+(P(w)-w) \partial_{1} D(P(w), P(W(w)))\right. \\
+(P(W(w))-W(w))\left(\partial_{1} D\left(P(W(w)), P(W(W(w)))-\partial_{1} D(P(W(w)), P(w))\right)\right] \\
+\left(P^{\prime}(W(w))-1\right)[D(P(W(w)), P(w))-D(P(W(w)), P(W(W(w)))] \\
+P^{\prime}(W(W(w))) W^{\prime}(W(w))(P(W(w))-w) \partial_{2} D(P(W(w)), P(W(W(w)))=0 .
\end{gathered}
$$

Differentiating this equation with respect to $w$ at $w=w^{M}$ (using $\partial_{1} \pi^{M}\left(p^{M}, p^{M}\right)=0$ and $\left.W^{\prime}\left(w^{M}\right)=1\right)$ leads to:

$$
W^{\prime \prime}\left(w^{M}\right)\left(p^{M}-w^{M}\right) \partial_{2} D\left(p^{M}, p^{M}\right)=-P^{\prime}\left(w^{M}\right)\left(\partial_{11}^{2} \pi^{M}\left(w^{M}, w^{M}\right)+\partial_{12}^{2} \pi^{M}\left(w^{M}, w^{M}\right)\right) .
$$

Thus $W^{\prime \prime}\left(w^{M}\right)$ has the same sign as $P^{\prime}\left(w^{M}\right)$. Evaluating $(A 2)$ at $w=w^{M}$ leads to: ${ }^{25}$

$$
P^{\prime}\left(w^{M}\right)\left(2 \partial_{1} D+\partial_{2} D+\left(p^{M}-w^{M}\right)\left(\partial_{11}^{2} D+\partial_{12}^{2} D\right)\right)=\partial_{1} D
$$

\footnotetext{
${ }^{25}$ The derivatives of the demand function being evaluated at $\left(p^{M}, p^{M}\right)$.
} 
The strict concavity of the profit function $\left(p_{1}-w^{M}\right) D\left(p_{1}, p_{2}\right)+\left(p_{2}-w^{M}\right) D\left(p_{2}, p_{1}\right)$ ensures that

$$
\partial_{1} D+\partial_{2} D+\left(p^{M}-w^{M}\right)\left(\partial_{11}^{2} D+\partial_{12}^{2} D\right)<0,
$$

which in turns establishes $P^{\prime}\left(w^{M}\right)>0$ and concludes the proof.

\section{A.2 Existence (and uniqueness) with polynomial beliefs}

We now restrict attention to the linear demand case:

$$
D\left(p_{i}, p_{j}\right)=\frac{1-\beta-p_{i}+\beta p_{j}}{1-\beta^{2}} .
$$

For each retailer's maximization program, the first-order condition is then necessary and sufficient and writes as:

$$
2 P_{i}\left(w_{i}\right)-\beta P_{j}\left(W_{j}\left(w_{i}\right)\right)=1-\beta+w_{i}
$$

Using $\left(P_{i}\right)$ we thus have:

$$
D\left(P_{i}\left(w_{i}\right), P_{j}\left(W_{j}\left(w_{i}\right)\right)\right)=\frac{P_{i}\left(w_{i}\right)-w_{i}}{1-\beta^{2}} .
$$

$R_{i}$ 's beliefs are such that $\partial_{2} \pi_{P}\left(w_{i}, W_{j}\left(w_{i}\right)\right)=0$, that is:

$$
\begin{aligned}
\left((1-\beta) c+\beta w_{i}-W_{j}\left(w_{i}\right)\right) & P_{j}^{\prime}\left(W_{j}\left(w_{i}\right)\right)+1-\beta-P_{j}\left(W_{j}\left(w_{i}\right)\right)+\beta P_{i}\left(w_{i}\right) \\
+2\left(P_{j}^{\prime}\left(W_{j}\left(w_{i}\right)\right)-1\right)\left(P_{j}\left(W_{j}\left(w_{i}\right)\right)-W_{j}\left(w_{i}\right)\right) & =0 .
\end{aligned}
$$

Let us now consider the polynomial solutions to the system consisting of equations $\left(\left(W_{i}\right),\left(P_{i}\right)\right)_{i=1,2}$ We denote by $n_{i}$ and $m_{i}$ the degrees of the polynomials $W_{i}\left(w_{j}\right)$ and $P_{i}\left(w_{i}\right)$, and by $\omega_{i, k}$ and $p_{i, k}$ the coefficients of their terms of degree $k$ :

$$
W_{i}(w)=\sum_{k=0}^{n_{i}} \omega_{i, k} w^{k} \text { and } P_{i}(w)=\sum_{k=0}^{m_{i}} \pi_{i, k} w^{k} .
$$

- Step 1: any polynomial solution is affine $\left(0 \leq m_{1}, m_{2}, n_{1}, n_{2} \leq 1\right)$

Consider $\left(P_{i}\right)$ :

$$
\underbrace{2 P_{i}\left(w_{i}\right)}_{\operatorname{deg}=m_{i}}-\underbrace{\beta P_{j}\left(W_{j}\left(w_{i}\right)\right)}_{\operatorname{deg}=m_{j} n_{j}}=\underbrace{1-\beta+w_{i}}_{\operatorname{deg}=1} .
$$

Three cases can arise:

1. $m_{i}<m_{j} n_{j}$. This implies $m_{i}=0$ and $m_{j}=n_{j}=1$. Then $\left(W_{i}\right)$ reduces to

$$
1-\beta-\pi_{i, 0}+\beta P_{j}\left(w_{j}\right)-2\left(\pi_{i, 0}-W_{i}\left(w_{j}\right)\right)=0
$$

and thus $n_{i}=1$.

2. $m_{i}>m_{j} n_{j}$. This implies $m_{i}=1$ and $m_{j} n_{j}=0$. Thus, either $m_{j}=0$ or $m_{j}>0$ and $n_{j}=0$. 
(a) The case $m_{j}=0$ is similar to case 1 (reverting the roles of $i$ and $j$ ).

(b) If $m_{j}>0$ then $n_{j}=0$ and $\left(P_{j}\right)$ reduces to:

$$
\begin{aligned}
2 P_{j}(w) & =\beta P_{i}\left(W_{i}(w)\right)+1-\beta+w \\
& =\beta\left(\pi_{i, 0}+\pi_{i, 1} W_{i}(w)\right)+1-\beta+w .
\end{aligned}
$$

and therefore $m_{j}=\max \left(n_{i}, 1\right)$. If $n_{i} \leq 1$, then no degree exceeds 1 . The only remaining case is $m_{j}=n_{j} \geq 2$. Since $m_{i}=1$ and $n_{j}=0$, equation $\left(P_{i}\right)$ leads to

$$
P_{i}(w)=\frac{1}{2}\left(1-\beta+\beta P_{j}\left(\omega_{j, 0}\right)+w\right) \Rightarrow P_{i}^{\prime}(w)=\frac{1}{2} .
$$

Differentiating $\left(W_{i}\right)$ and $\left(P_{j}\right)$ twice then yields respectively

$$
\beta P_{j}^{\prime \prime}(w)=\frac{1}{2} W_{i}^{\prime \prime}(w) \text { and } \beta W_{i}^{\prime \prime}(w)=4 P_{j}^{\prime \prime}(w),
$$

implying $2 \beta^{2} P_{j}^{\prime \prime}(w)=W_{i}^{\prime \prime}(w)=4 P_{j}^{\prime \prime}(w)\left(\neq 0\right.$ since $\left.n_{i}=m_{j} \geq 2\right)$, a contradiction.

3. $m_{i}=m_{j} n_{j} \geq 1$. In this case, either $m_{j}=m_{i} n_{i} \geq 1$ or all degrees are equal or lower than 1 (simply inverting the roles played by $i$ and $j$ in cases 1 and 2 ).

But $m_{i}=m_{j} n_{j} \geq 1$ and $m_{j}=m_{i} n_{i} \geq 1$ imply $n_{i}=n_{j}=1$ and $m_{j}=m_{i}=m \geq 1$. The only interesting case is when $m \geq 2$. Then $\left(W_{j}\right)$ yields:

$$
\begin{aligned}
& \underbrace{\left((1-\beta) c+\beta w_{i}-W_{j}\left(w_{i}\right)\right) P_{j}^{\prime}\left(W_{j}\left(w_{i}\right)\right)+1-\beta-P_{j}\left(W_{j}\left(w_{i}\right)\right)+\beta P_{i}\left(w_{i}\right)}_{\text {deg } \leq m} \\
& \underbrace{+2\left(P_{j}^{\prime}\left(W_{j}\left(w_{i}\right)\right)-1\right)\left(P_{j}\left(W_{j}\left(w_{i}\right)\right)-W_{j}\left(w_{i}\right)\right)}_{\operatorname{deg}=2 m-1 \geq 3}=0,
\end{aligned}
$$

which contradicts $m>1$.

This concludes the proof and shows that polynomial solutions must be affine.

- Step 2: any equilibrium with affine wary beliefs satisfies $\pi_{1,1}=\pi_{2,1}$ and $\omega_{1,1}=\omega_{2,1}$.

With affine beliefs, $\left(P_{i}\right)$ reduces to

$$
2\left(\pi_{i, 0}+\pi_{i, 1} w\right)-\beta\left(\pi_{j, 0}+\pi_{j, 1}\left(\omega_{j, 0}+\omega_{j, 1} w\right)\right)=1-\beta+w
$$

and since it holds for any $w$, it implies

$$
\begin{aligned}
2 \pi_{i, 0}-\beta \pi_{j, 0} & =1-\beta+\beta \pi_{j, 1} \omega_{j, 0}, \\
2 \pi_{i, 1}-\beta \pi_{j, 1} \omega_{j, 1} & =1
\end{aligned}
$$

$\left(A 8_{i}\right)$ and $\left(A 8_{j}\right)$ yield

$$
\pi_{i, 1}=\frac{2+\beta \omega_{j, 1}}{4-\beta^{2} \omega_{1,1} \omega_{2,1}}
$$


and thus:

$$
\left(4-\beta^{2} \omega_{1,1} \omega_{2,1}\right)\left(\pi_{i, 1}-\pi_{j, 1}\right)=\beta\left(\omega_{j, 1}-\omega_{i, 1}\right)
$$

Similarly, $\left(W_{j}\right)$ implies:

$$
\begin{aligned}
& 2\left(\pi_{j, 1}^{2}-3 \pi_{j, 1}+1\right) \omega_{j, 0}=-1+\beta-(1-\beta) c \pi_{j, 1}+\left(3-2 \pi_{j, 1}\right) \pi_{j, 0}-\beta \pi_{i, 0}, \\
& 2\left(\pi_{j, 1}^{2}-3 \pi_{j, 1}+1\right) \omega_{j, 1}=-\beta\left(\pi_{i, 1}+\pi_{j, 1}\right) .
\end{aligned}
$$

Using ( $A 8)$ to replace $\pi_{j, 1} \omega_{j, 1}$ in (A11) yields:

$$
6+\beta^{2}\left(\pi_{i, 1}+\pi_{j, 1}\right)+4 \pi_{i, 1} \pi_{j, 1}+2 \beta \omega_{j, 1}=12 \pi_{i, 1}-2 \pi_{j, 1} .
$$

Substracting $\left(A 12_{j}\right)$ to $\left(A 12_{i}\right)$, we have:

$$
5\left(\pi_{i, 1}-\pi_{j, 1}\right)=\beta\left(\omega_{j, 1}-\omega_{i, 1}\right),
$$

which, combined with (A9), imposes:

$$
\left(1+\beta^{2} \omega_{1,1} \omega_{2,1}\right)\left(\pi_{i, 1}-\pi_{j, 1}\right)=0 .
$$

But the second-order conditions of the manufacturer's program impose $0 \leq \omega_{1,1} \omega_{2,1} \leq 1 .^{26}$ Therefore, (A14) imposes $\pi_{1,1}=\pi_{2,1}=\pi_{1}$ and thus $\omega_{1,1}=\omega_{2,1}=\omega_{1}$.

Given the symmetry, $(A 8)$ and (A11) simplify to

$$
\begin{aligned}
\beta \omega_{1} \pi_{1} & =2 \pi_{1}-1, \\
\left(\pi_{1}^{2}-3 \pi_{1}+1\right) \omega_{1} & =-\beta \pi_{1} .
\end{aligned}
$$

- Step 3: there exists a unique pair $\left(\pi_{1}^{*}, \omega_{1}^{*}\right)$ satisfying (8) and (8) as well as second-order conditions.

Let us use $(A 15)$ to eliminate $\omega_{1}$ in $(A 16)$ :

$$
\begin{aligned}
& \left(\pi_{1}^{2}-3 \pi_{1}+1\right)\left(2 \pi_{1}-1\right)=-\beta^{2} \pi_{1}^{2} \\
\Leftrightarrow & 2 \pi_{1}^{3}-\left(7-\beta^{2}\right) \pi_{1}^{2}+5 \pi_{1}-1=0 .
\end{aligned}
$$

The left-hand side is a polynomial $\varphi$ of degree 3 such that:

$$
\varphi(0)=-1<0<\varphi\left(\frac{1}{2}\right)=\frac{\beta^{2}}{4} \text { and } \varphi(1)=-\left(1-\beta^{2}\right)<0<\varphi(+\infty) .
$$

Therefore, $\varphi$ has three roots: one in $] 0, \frac{1}{2}[$, one in $] \frac{1}{2}, 1[$ and one in $] 1,+\infty[$.

\footnotetext{
${ }^{26}$ Beliefs satisfy $\partial_{1} \pi^{P}\left(W_{1}(w), w\right)=0$ and $\partial_{2} \pi^{P}\left(w, W_{2}(w)\right)=0$. Therefore, $\omega_{i, 1}=-\partial_{12}^{2} \pi^{P} / \partial_{i i}^{2} \pi^{P}$ and the second-order conditions of the manufacturer's program impose $\omega_{1,1} \omega_{2,1}=\left(\partial_{12}^{2} \pi^{P}\right)^{2} / \partial_{11}^{2} \pi^{P} \partial_{22}^{2} \pi^{P}>0$.
} 
Using the retailers's responses, the manufacturer's profit can be expressed as

$$
\begin{aligned}
\pi_{P}\left(w_{1}, w_{2}\right)= & {\left[\left(w_{1}-c\right) D\left(P_{1}\left(w_{1}\right), P_{2}\left(w_{2}\right)\right)+\frac{\left(P_{1}\left(w_{1}\right)-w_{1}\right)^{2}}{1-\beta^{2}}\right.} \\
& \left.+\left(w_{2}-c\right) D\left(P_{2}\left(w_{2}\right), P_{1}\left(w_{1}\right)\right)+\frac{\left(P_{2}\left(w_{2}\right)-w_{2}\right)^{2}}{1-\beta^{2}}\right] .
\end{aligned}
$$

Therefore:

$$
\begin{aligned}
\partial_{1} \pi_{P}\left(w_{1}, w_{2}\right)= & \frac{\pi_{1}}{1-\beta^{2}}\left(-\left(w_{1}-c\right)+\beta\left(w_{2}-c\right)\right)+D\left(P_{1}\left(w_{1}\right), P_{2}\left(w_{2}\right)\right) \\
& +\frac{2}{1-\beta^{2}}\left(\pi_{1}-1\right)\left(P_{1}\left(w_{1}\right)-w_{1}\right),
\end{aligned}
$$

and

$$
\begin{aligned}
\partial_{11}^{2} \pi_{P} & =\frac{2}{1-\beta^{2}}\left(\pi_{1}^{2}-3 \pi_{1}+1\right), \\
\partial_{12}^{2} \pi_{P} & =\frac{2}{1-\beta^{2}} \beta \pi_{1} .
\end{aligned}
$$

A first necessary condition is $\partial_{11}^{2} \pi_{P} \leq 0$, that is $\pi_{1}^{2}-3 \pi_{1}+1 \leq 0$. Together with $(A 17)$, it implies

$$
2 \pi_{1}-1>0 \Leftrightarrow \pi_{1}>\frac{1}{2} \text {. }
$$

A second necessary condition is $\left(\partial_{11}^{2} \pi_{P}\right)^{2} \geq\left(\partial_{12}^{2} \pi_{P}\right)^{2}$, which is equivalent to

$$
\begin{gathered}
\left(\pi_{1}^{2}-3 \pi_{1}+1\right)^{2}-\beta^{2} \pi_{1}^{2} \geq 0 \\
\Leftrightarrow \underbrace{-\left(\pi_{1}^{2}-3 \pi_{1}+1\right)\left(2 \pi_{1}-1\right)-\beta^{2} \pi_{1}^{2}}_{=0 \text { from }(A 17)}-\pi_{1}\left(1-\pi_{1}\right)\left(\pi_{1}^{2}-3 \pi_{1}+1\right) \geq 0 \\
\Leftrightarrow \pi_{1}\left(1-\pi_{1}\right) \geq 0 \Leftrightarrow 0 \leq \pi_{1} \leq 1 .
\end{gathered}
$$

Together, $(A 20)$ and $(A 21)$ impose that the solution of $(A 18)$ is the unique root of $\varphi$ in $] \frac{1}{2}, 1[$. $(A 15)$ then uniquely defines $\omega_{1}^{*}$ :

$$
\omega_{1}^{*}=\frac{2 \pi_{1}^{*}-1}{\beta \pi_{1}^{*}}>0
$$

- Step 4: the solution of the overall program, if it exists, is symmetric.

Substracting $\left(A 7_{j}\right)$ from $\left(A 7_{i}\right)$ and $\left(A 10_{j}\right)$ from $\left(A 10_{i}\right)$ yields respectively:

$$
\begin{aligned}
(2+\beta)\left(\pi_{1,0}-\pi_{2,0}\right) & =\beta \pi_{1}\left(\omega_{1,0}-\omega_{2,0}\right), \\
2\left(\pi_{1}^{2}-3 \pi_{1}+1\right)\left(\omega_{1,0}-\omega_{2,0}\right) & =\left(3+\beta-2 \pi_{1}\right)\left(\pi_{1,0}-\pi_{2,0}\right),
\end{aligned}
$$

thus implying

$$
2(2+\beta)\left(\pi_{1}^{2}-3 \pi_{1}+1\right)\left(\pi_{1,0}-\pi_{2,0}\right)=\beta \pi_{1}\left(3-\beta-2 \pi_{1}\right)\left(\pi_{1,0}-\pi_{2,0}\right) .
$$

But then $\pi_{1}^{2}-3 \pi_{1}+1<0$ and $\frac{1}{2}<\pi_{1}<1$ imply $\pi_{1,0}=\pi_{2,0}$ and thus $\omega_{1,0}=\omega_{2,0}$. 


\section{- Step 5: there exists a unique solution.}

Given the symmetry, $(A 7)$ and $(A 10)$ reduce to:

$$
\begin{aligned}
(2-\beta) \pi_{0}-\beta \pi_{1} \omega_{0} & =1-\beta, \\
\left(3-\beta-2 \pi_{1}\right) \pi_{0}-2\left(\pi_{1}^{2}-3 \pi_{1}+1\right) \omega_{0} & =1-\beta+(1-\beta) c \pi_{1} .
\end{aligned}
$$

The determinant is

$$
-2(2-\beta)\left(\pi_{1}^{2}-3 \pi_{1}+1\right)+\beta \pi_{1}\left(3-\beta-2 \pi_{1}\right)>0 .
$$

It is positive since $\left(\pi_{1}^{2}-3 \pi_{1}+1\right)<0$ and $\frac{1}{2}<\pi_{1}<1$. Therefore, $(A 21)$ and $(A 22)$ uniquely define $\pi_{0}^{*}$ and $\omega_{0}^{*}$ as functions of $\pi_{1}$. The equilibrium retail price is then

$$
p^{*}=\frac{1-\beta+w^{*}}{2-\beta},
$$

where

$$
w^{*}=W\left(w^{*}\right)=\omega_{0}^{*}\left(\pi_{1}^{*}\right)+\omega_{1}^{*}\left(\pi_{1}^{*}\right) w^{*}=\frac{\omega_{0}^{*}\left(\pi_{1}^{*}\right)}{1-\omega_{1}^{*}\left(\pi_{1}^{*}\right)} .
$$

\section{B Resale Price Maintenance: proof of Proposition 7}

We show here that with RPM there exists a symmetric equilibrium, with affine wary beliefs based on offered prices, that sustains the monopoly price $p^{M}$. Note that with RPM, interim observability does not matter, since retail prices are contractually set ex ante.

Receiving an offer $\left(f_{i}, w_{i} ; p_{i}\right), R_{i}$ anticipates that $R_{j}$ has accepted the contract $\left(W\left(w_{i}, p_{i}\right)\right.$, $\left.F\left(w_{i}, p_{i}\right) ; P\left(w_{i}, p_{i}\right)\right)$ and accepts the offer if and only if

$$
f_{i} \leq\left(p_{i}-w_{i}\right) D_{i}\left(p_{i}, P\left(w_{i}, p_{i}\right)\right) .
$$

The beliefs $W, F$ and $P$ must therefore satisfy

$$
F(w, p)=(P(w, p)-W(w, p)) D(P(w, p), P(W(w, p), P(w, p)))
$$

and

$(W(w, p), P(w, p))=\underset{\left(w_{2}, p_{2}\right)}{\arg \max }\left[(w-c) D\left(p, p_{2}\right)+\left(w_{2}-c\right) D\left(p_{2}, p\right)+\left(p_{2}-w_{2}\right) D\left(p_{2}, P\left(w_{2}, p_{2}\right)\right)\right]$.

The first-order conditions are:

$$
\begin{aligned}
\beta(p-P(W, P))+(P(w, p)-W(w, p)) \frac{\partial P}{\partial w}(W, P) & =0 \\
(1-\beta)(1-c)+\beta w-2 P(w, p)+\beta P(W, P)-\beta(P(w, p)-W(w, p)) \frac{\partial P}{\partial p}(W, P) & =0 .
\end{aligned}
$$

In equilibrium, we must also have

$$
P\left(w^{*}, p^{*}\right)=p^{*} \text { and } W\left(w^{*}, p^{*}\right)=w^{*} .
$$


- Affine beliefs leading to the monopoly price

We consider beliefs of the form

$$
\begin{aligned}
P(w, p) & =\alpha_{P}+\omega_{P} w+\pi_{P} p, \\
W(w, p) & =\alpha_{W}+\omega_{W} w+\pi_{W} p,
\end{aligned}
$$

and look for an equilibrium where $w^{*}=p^{*}=p^{M}=\frac{1+c}{2}$. (B1) imposes

$$
\begin{aligned}
\alpha_{P} & =\left(1-\pi_{P}-\omega_{P}\right) p^{M}=\frac{\left(1-\pi_{P}-\omega_{P}\right)(1+c)}{2}, \\
\alpha_{W} & =\left(1-\pi_{W}-\omega_{W}\right) p^{M}=\frac{\left(1-\pi_{W}-\omega_{W}\right)(1+c)}{2} .
\end{aligned}
$$

Then, the first-order conditions lead to:

$$
\begin{aligned}
1-\pi_{P}^{2}+\omega_{P}^{2}-2 \omega_{P}\left(\pi_{W}+\omega_{W}\right) & =0, \\
\omega_{P}\left(\omega_{P}-\pi_{P}-2 \omega_{W}\right) & =0, \\
1-\pi_{P}^{2}+\omega_{P}\left(\pi_{P}-2 \pi_{W}\right) & =0, \\
\beta\left(\pi_{P}-\omega_{P}\right)\left(\pi_{W}+\omega_{W}\right)-\beta-2\left(\pi_{P}+\omega_{P}\right)\left(1-\beta \pi_{P}\right) & =0, \\
\beta\left(\pi_{P}-\omega_{P}\right) \omega_{W}-\beta+2 \omega_{P}\left(1-\beta \pi_{P}\right) & =0, \\
\beta\left(\pi_{P}-\omega_{P}\right) \pi_{W}+2 \pi_{P}\left(1-\beta \pi_{P}\right) & =0 .
\end{aligned}
$$

It is easy to check that $(B 4)=(B 5)+(B 6)$ and $(B 7)=(B 8)+(B 9)$. Equations $(B 8)$ and $(B 9)$ lead to:

$$
\omega_{W}=\frac{\beta-2 \omega_{P}\left(1-\beta \pi_{P}\right)}{\beta\left(\pi_{P}-\omega_{P}\right)} \text { and } \pi_{W}=\frac{2 \pi_{P}\left(1-\beta \pi_{P}\right)}{\beta\left(\pi_{P}-\omega_{P}\right)} .
$$

Assuming that $\omega_{P} \neq 0$, subtracting $(B 6)$ from $\frac{\pi_{P}}{\omega_{P}}(B 5)$ yields

$$
\frac{3 \pi_{P}-\omega_{P}}{\pi_{P}-\omega_{P}}=0 \Leftrightarrow \omega_{P}=3 \pi_{P}
$$

Then, rewriting (B6) using (B10) and (B11), it comes:

$$
8 \beta \pi_{P}^{2}-6 \pi_{P}+\beta=0 \Leftrightarrow \pi_{P}=\frac{3 \pm \sqrt{9-8 \beta^{2}}}{8 \beta} .
$$

\section{- Second-order conditions}

We now show that one of the two above solutions satisfies the second-order conditions of the overall program. The manufacturer's maximization program is:

$$
\begin{array}{rr}
\left(w_{1}^{*}, p_{1}^{*}, w_{2}^{*}, p_{2}^{*}\right)=\underset{\left(w_{1}, p_{1}, w_{2}, p_{2}\right)}{\arg \max } \quad\left[\left(w_{1}-c\right) D\left(p_{1}, p_{2}\right)+\left(p_{1}-w_{1}\right) D\left(p_{1}, P\left(w_{1}, p_{1}\right)\right)\right. \\
\left.+\left(w_{2}-c\right) D\left(p_{2}, p_{1}\right)+\left(p_{2}-w_{2}\right) D\left(P\left(w_{2}, p_{2}\right), p_{2}\right)\right] .
\end{array}
$$


Using the linear form of function $P$, the Hessian matrix only depends on $\pi_{P}$ and $\omega_{P}$ and is equal to

$$
H\left(\omega_{P, \pi_{P}}\right)=\left(\begin{array}{cccc}
-2 \beta \pi_{P} & \beta\left(\omega_{P}-\pi_{P}\right) & 0 & \beta \\
\beta\left(\omega_{P}-\pi_{P}\right) & -2\left(1-\beta \pi_{P}\right) & \beta & 0 \\
0 & \beta & -2 \beta \pi_{P} & \beta\left(\omega_{P}-\pi_{P}\right) \\
\beta & 0 & \beta\left(\omega_{P}-\pi_{P}\right) & -2\left(1-\beta \pi_{P}\right)
\end{array}\right) .
$$

Using (B11) the matrix can be simplified into:

$$
H\left(\pi_{P}\right)=\left(\begin{array}{cccc}
-2 \beta \pi_{P} & 2 \beta \pi_{P} & 0 & \beta \\
2 \beta \pi_{P} & -2\left(1-\beta \pi_{P}\right) & \beta & 0 \\
0 & \beta & -2 \beta \pi_{P} & 2 \beta \pi_{P} \\
\beta & 0 & 2 \beta \pi_{P} & -2\left(1-\beta \pi_{P}\right)
\end{array}\right) .
$$

The four eigenvalues of the matrix $H\left(\pi_{P}\right)$ are given by:

$$
\lambda\left(\pi_{P}\right)=-1-2 \beta \pi_{P} \pm \sqrt{1-8 \beta \pi_{P}+\beta^{2}\left(1 \pm 4 \pi_{P}+20 \pi_{P}^{2}\right)} .
$$

It can then be checked that the matrix $H\left(\frac{3-\sqrt{9-8 \beta^{2}}}{8 \beta}\right)$ is definite negative (the four eigenvalues are strictly negative). This ensures that there exists a symmetric equilibrium with affine wary beliefs leading to the monopoly prices and profit. 


\section{References}

[1] Caprice, S., "Multilateral Vertical Contracting with an Alternative Sourcing: Discrimination and Non-discrimination", Mimeo (2002).

[2] Crémer, J. and Riordan, M., "On Governing Multilateral Transactions with Bilateral Contracts," Rand Journal of Economics, Vol. 18 (1987), pp. 436-451.

[3] De Graba, P., "Most-Favored-Customer Clauses and Multilateral Contracting: WhenNondiscrimination Implies Uniformity," Journal of Economics and Management Strategy, Vol. 5(1996), pp. 565-579.

[4] and Postlewaite, A., "Exclusivity Clauses and Best Price Policies in Input Markets," Journal of Economics and Management Strategy, Vol. 1 (1992), pp. 423-454.

[5] Hart, O. and Tirole, J., "Vertical Integration And Market Foreclosure," Brookings Papers on Economic Activity, (1990), pp. 205-276.

[6] Horn, H. and Wolinsky, A., "Bilateral Monopolies and Incentives for Merger," Rand Journal of Economics, Vol. 19 (1988), pp.408-419.

[7] Kreps, D. and Scheinkman, J., "Quantity Precommitment and Bertrand Competition Yields Cournot Outcomes," Bell Journal of Economics, Vol. 14 (1983), pp. 326-337.

[8] Martin, S., Normann, H.T. and Snyder, C., "Vertical Foreclosure in Experimental Markets," Rand Journal of Economics Vol. 32(2001), pp. 466-496.

[9] Marx, L. and Shaffer, G., "Nondiscrimination clauses in Vertical Contracts, (2002)" Duke/UNC Micro-Theory Working Paper no. 14.

[10] McAfee, P. and Schwartz, M., "Opportunism in Multilateral Contracting: Nondiscrimination, Exclusivity and Uniformity," American Economic Review Vol. 84 (1994), pp. 210-230.

[11] , "The Non-Existence of Pairwise-proof Equilibrium," Economics Letters, Vol. 49 (1995), pp. 251-259.

[12] O'Brien, D.P. and Shaffer, G., "Vertical Control with Bilateral Contracts," Rand Journal of Economics Vol. 23(1992), pp. 299-308.

[13] Rey, P. and Tirole, J., "A Primer on Foreclosure," forthcoming in Handbook of Industrial Organization, Vol. 3 (1997), M. Armstrong and R.H. Porter eds., North Holland.

[14] Segal, I. and Whinston, M.D., "Robust Predictions for Bilateral Contracting with Externalities", Econometrica Vol. 71 (2003), pp. 757-791. 